\title{
Evaluation of Fungal Growth on Olive-Mill Wastewaters Treated at High Temperature and by High-Pressure Homogenization
}

\author{
Francesca Cibelli, Antonio Bevilacqua, Maria L. Raimondo, Daniela Campaniello, \\ Antonia Carlucci, Claudio Ciccarone, Milena Sinigaglia and Maria R. Corbo*
}

Department of the Science of Agriculture, Food and Environment, University of Foggia, Foggia, Italy

\section{OPEN ACCESS}

Edited by:

Rosalba Lanciotti,

Università di Bologna, Italy

Reviewed by:

Wei Shi,

North Carolina State University,

United States

David Gramaje,

Instituto de Ciencias de la Vid y del

Vino (ICW), Spain

*Correspondence:

Maria R. Corbo

mariarosaria.corbo@unifg.it

Specialty section:

This article was submitted to

Food Microbiology,

a section of the journal

Frontiers in Microbiology

Received: 13 October 2017 Accepted: 04 December 2017 Published: 14 December 2017

Citation:

Cibelli F, Bevilacqua A, Raimondo $M L$ Campaniello D, Carlucci A,

Ciccarone $C$, Sinigaglia $M$ and Corbo MR (2017) Evaluation of Fungal Growth on Olive-Mill Wastewaters

Treated at High Temperature and by High-Pressure Homogenization.

Front. Microbiol. 8:2515. doi: 10.3389/fmicb.2017.02515
Reuse of olive mill wastewaters (OMWWs) in agriculture represents a significant challenge for health and safety of our planet. Phytotoxic compounds in OMWW generally prohibit use of untreated OMWWs for agricultural irrigation or direct discharge into surface waters. However, pretreated OMWW can have positive effects on chemical and microbiological soil characteristics, to fight against fungal soil-borne pathogens. Low amounts of OMWW following thermal (TT-OMWW) and high-pressure homogenization $(\mathrm{HPH}-\mathrm{OMWW}$ ) pretreatments counteracted growth of some of 12 soil-borne and/or pathogenic fungi examined. With fungal growth measured as standardized change in time to half maximum colony diameter, $\Delta \tau$, overall, HPH-OMWW showed increased bioactivity, as increased mean $\Delta \tau$ from 3.0 to 4.8 days. Principal component analysis highlighted two fungal groups: Colletotrichum gloeosporioides, Alternaria alternata, Sclerotium rolfsii, and Rosellinia necatrix, with growth strongly inhibited by the treated OMWWs; and Aspergillus ochraceus and Phaeoacremonium parasiticum, with stimulated growth by the treated OMWWs. As a non-thermal treatment, HPH-OMWW generally shows improved positive effects, which potentially arise from preservation of the phenols.

Keywords: fungi, high-pressure of homogenization, thermal treatment, olive mill wastewater, antifungal activity

\section{INTRODUCTION}

Phenols, long chain fatty acids and other phytotoxic and inhibitory compounds are the major constituents of olive-mill wastewater (OMWW); however, the exact composition of OMWW is greatly variable and relies upon some factors like region of production process, milling conditions (Niaounakis and Halvadakis, 2006).

Phenols and other compounds limit the use of OMWW in agriculture, as they could affect the chemical and physical traits of soil (porosity and $\mathrm{pH}$ ) and the germination of seeds (Marrara et al., 2002; El Hadrami et al., 2004; Mekki et al., 2006). Moreover, OMWW, when discharged directly into surface waters, can discolor streams and rivers (Niaounakis and Halvadakis, 2006).

However, OMWW can be also a valuable source for many purposes (production of fertilizers, recovery of antioxidants, and production of biopolymers, biogas and animal feed) (Morillo et al., 2009). In a recent study, Disciglio et al. (2015) investigated the effects of irrigation with treated agroindustrial wastewater on soil and fungal populations. Compared to groundwater, wastewater had 
significantly higher electrical conductivity, total suspended solids, sodium, calcium, magnesium, potassium and sodium adsorption ratios, chemical oxygen demand, biological oxygen demand over 5 days, ammonium-nitrogen, and phenol, bicarbonate, phosphate, sulfate and chloride contents. Most of these characteristics were significantly higher also in the wastewater-irrigated soil. During the tomato cultivation, there were significant shifts in the composition of the soil microbial community. Saprophytic species increased in the wastewatertreated soil, while plant pathogens, such as Fusarium oxysporum, progressively decreased.

Other studies have reported that when the high content of organic matter in wastewater (compared to fresh water) decomposes in the soil, this can increase the population of saprophytic fungi. Some of these can act as antagonists of soilborne plant pathogens, such as Trichoderma spp., Fusarium spp., and Aspergillus spp. (Manici et al., 2004). Thus, the use of treated agro-industrial wastewater can provide great benefits to agriculture as well as to environmental recovery, because the use of intensive agricultural systems can lead to a major buildup of soil-borne plant pathogens, as reported by Garibaldi and Gullino (1995). Lops et al. (2008) showed that milling waste could be effective in the control of some fungal diseases and for plant growth. This was believed to arise through the polyphenolic compounds that it contains, which can be useful against fungal soil-borne pathogens that cause root rot.

The use of OMWW in agriculture also pose the problem of a preliminary treatment due to the high level of the naturally occurring microbiota (Sinigaglia et al., 2010). Thermal treatment could be a possible approach, but it could also result in some undesirable physico-chemical changes, like phenol degradation. Thus, non-thermal technologies have been proposed to provide cold pasteurization, which would reduce this heat damage. Highpressure homogenization $(\mathrm{HPH})$ and high hydrostatic pressure are promising non-thermal technologies that are particularly suitable for continuous production of liquid foods while limiting thermal damage (Xi et al., 2009; Suárez-Jacobo et al., 2010; Calligaris et al., 2012; Varela-Santos et al., 2012; VelázquezEstrada et al., 2013; Amador-Espejo et al., 2014; Yu et al., 2014; Wibowo et al., 2015).

The focus of this study was on OMWW as a tool to control and/or inhibit soil-borne fungi in agriculture. The OMWW was initially treated and stabilized to reduce the naturally occurring microbiota to acceptable levels. The two approaches used here were conventional thermal treatment (TT-OMWW) and $\mathrm{HPH}(\mathrm{HPH}-\mathrm{OMWW})$, to determine whether these different approaches act on bioactivities in different ways.

\section{MATERIALS AND METHODS \\ Olive-Mill Wastewater Collection and Testing}

The OMWW used in this study was collected from a local olive mill in the province of Foggia (southern Italy) that operated using both continuous and traditional oil extraction methods. Thus, this OMWW was a mixture of the wastewaters from both of these extraction methods. It was subjected to $\mathrm{pH}$ and phenolics determinations using the methods described by Bray and Thrope (1954). Moreover, proteins and reducing sugar were assessed as respectively reported by Bradford (1976) and De Clerk (1963, Fehling method).

\section{Olive-Mill Wastewater Treatments}

In order to obtain TT-OMWW used in this study, OMWW was diluted in agar and sterilized at $121^{\circ} \mathrm{C}$ for $20 \mathrm{~min}$.

In order to obtain the HPH-OMWW, OMWW was filtered through Miracloth paper (Calbiochem, Germany), and processed using a high-pressure homogenizer (PANDA 2K; Niro Soavi s.p.a., Parma, Italy), at $150 \mathrm{MPa}$. The homogenizer was a two-valve device. The first valve (a ball valve, indicated by the manufacturer as the "main valve") worked at a maximum pressure of $150 \mathrm{MPa}$ and was used for the homogenization. The second valve was designed for emulsion preparation and micronization treatment, and worked at a maximum pressure of $15 \mathrm{MPa}$. In the present study, the $\mathrm{HPH}$ was performed only through the main valve. Before each treatment, the equipment was cleaned with sterilized distilled water at $70^{\circ} \mathrm{C}$, and cooled with sterilized distilled water to obtain an exit temperature of the samples of $<35^{\circ} \mathrm{C}$.

\section{Fungi}

Twelve reference fungal species from a fungal pool assayed on different OMWWs in a previous study (Bevilacqua et al., 2017) were used to examine their growth on TT-OMWW and HPHOMWW in the present study. Information about these fungal species is given in Table 1, which were: Lasiodiplodia theobromae (Pat.) Griffon \& Maubl., Colletotrichum gloeosporioides (Penz.) Penz. \& Sacc., F. oxysporum E. F. Sm. \& Swingle, Phaeoacremonium parasiticum (Ajello, Georg \& C. J. K. Wang) W. Gams, Crous \& M. J. Wingf., Penicillium italicum Wehmer, Aspergillus niger Tiegh., Aspergillus ochraceus G. Wilh., Alternaria alternata (Fr.) Keissl., Trichoderma sp. Pers., Sclerotium rolfsii Sacc., Rosellinia necatrix Berl. ex Prill., and Diaporthe amygdali Udayanga, Crous \& K. D. Hyde.

\section{Growth Rates on the Treated Olive-Mill Wastewater Minimal Media}

Fungal growth was initially assessed in a minimal culture medium using TT-OMWW as the only source of nutrition. The TT-OMWW was diluted in distilled water containing $15 \mathrm{~g}$ $\mathrm{L}^{-1}$ agar (Agar Technical n.3; Oxoid Ltd., UK) to three final concentrations: 5,10 , and $15 \%$. These media were sterilized at $121^{\circ} \mathrm{C}$ for $20 \mathrm{~min}$ (as the thermal treatment), and then poured into sterile 55-mm-diameter Petri dishes. The fungi were aseptically inoculated using $2-\mathrm{mm}$ mycelium plugs cut from the colony margins of 7-10-day-old cultures of the target fungi in Petri dishes, with each assay run in triplicate.

Similarly, the fungal growth was assessed in a minimal culture medium using HPH-OMWW as the only source of nutrition. The $\mathrm{HPH}-\mathrm{OMWW}$ was also diluted in distilled water containing $15 \mathrm{~g}$ $\mathrm{L}^{-1}$ agar (Agar Technical n.3; Oxoid Ltd., UK) to the same three final concentrations: 5,10 , and $15 \%$. These media were poured 
TABLE 1 | Details of the fungal species used in this study.

\begin{tabular}{|c|c|c|c|c|c|}
\hline Fungal species & Host & Locality & Identification tools & Reference or collection & Abbreviation \\
\hline Alternaria alternata & Olea europea & Cerignola, Foggia, Italy & MOR & Carlucci et al., 2015b & Aal \\
\hline Aspergillus niger & Oil-mill wastewater & Cerignola, Foggia, Italy & MOR & Dept. SAFE & Ang \\
\hline Aspergillus ochraceus & Soil & Stornarella, Foggia, Italy & MOR & Dept. SAFE & Aoc \\
\hline Colletotrichum gloeosporioides & Olea europea & Matino, Lecce, Italy & MOR & Dept. SAFE & Cgd \\
\hline Diaporthe amygdali & Prunus dulcis & Matino, Lecce, Italy & $\mathrm{MC}$ & Dept. SAFE & Dag \\
\hline Fusarium oxysporum & Olea europea & Presicce, Lecce, Italy & $\mathrm{MC}$ & Dept. SAFE & Fx \\
\hline Lasiodiplodia theobromae & Vitis vinifera & Cerignola, Foggia, Italy & $\mathrm{MC}$ & Carlucci et al., 2015a & Bot \\
\hline Penicillium italicum & Soil & Stornarella, Italy & MOR & Dept. SAFE & Pit \\
\hline Phaeoacremonium parasiticum & Olea europea & Cerignola, Foggia, Italy & $\mathrm{MC}$ & Carlucci et al., 2015b & Pmp \\
\hline Rosellinia necatrix & Olea europea & Cerignola, Foggia, Italy & MOR & Dept. SAFE & $\operatorname{Rn} x$ \\
\hline Sclerotium rolfsii & Solanum lycopersicum & Stornarella, Foggia, Italy & MOR & Dept. SAFE & Sri \\
\hline Trichoderma sp. & Soil & Stornarella, Foggia, Italy & MOR & Dept. SAFE & Trc \\
\hline
\end{tabular}

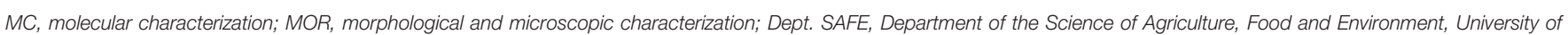
Foggia, Foggia, Italy.

directly into sterile 55-mm-diameter Petri dishes. The fungi were inoculated as described above, with each assay run in triplicate.

The media inoculated with TT-OMWW and HPH-OMWW were then incubated at $23 \pm 2{ }^{\circ} \mathrm{C}$ in the dark. The control cultures that used PDA as the positive control were prepared and incubated in parallel.

The colony diameters were measured and compared with those of the PDA control plates at intervals of 48 h over 21 days, to determine the radial growth of these fungi under these minimal growth conditions with TT-OMWW and HPH-OMWW as the only sources of nutrition (Carlucci et al., 2012).

\section{Statistical Analysis and Modeling}

The experiments were performed in triplicate. Fungal growth was modeled using a logistic equation as modified by Dantigny et al. (2011), and given in Equation (1):

$$
D=\frac{D_{\max }}{1+\exp [k(\tau-t)]}
$$

where $\mathrm{D}$ is the diameter of the fungal colony at the chosen time, $D_{\max }$ is the maximum diameter of the fungal colony (here set as $55 \mathrm{~mm}$; i.e., the diameter of the plates), $k$ is the rate of fungal growth $\left(\mathrm{mm}\right.$ day $\left.^{-1}\right), \tau$ is the time to attain half $D_{\max }$ (days), and $\mathrm{t}$ is the chosen time of the analysis (days).

The differences among the fitting parameters from OMWW at different concentrations were assessed through one-way ANOVA; the test of Tukey was used as the post-hoc test $(P<0.05)$ (Statistica for Windows).

Data fitting was performed using the Statistica for Windows software (version 12.0; Statsoft, Tulsa, OK, USA), with a leastsquares approach. After this primary modeling step, secondary modeling was performed. Before this step, $\tau$ was standardized as given in Equation (2):

$$
\tau=\tau_{O M W}-\tau_{c}
$$

where $\tau_{O M W}$ and $\tau_{c}$ are the $\tau$ values from the media supplemented with TT-OMWW or HPH-OMWW and from the control medium with PDA, respectively. A positive $\Delta \tau$ indicates inhibition of fungal growth due to the TT-OMWW and $\mathrm{HPH}-$ OMWW, whereas a negative $\Delta \tau$ indicates that the fungal growth was promoted.

This $\Delta \tau$ was then used as the dependent variable to run multi-factorial analysis of variance (ANOVA). The categorical predictors (i.e., independent variables) were the treatment (TTOMWW, HPH-OMWW) (T), the amount of these OMWWs additions (5, 10, 15\%) (A), and the fungal species assayed (F). Such multi-factorial ANOVA offers two kinds of outputs:

- A table of standardized effects that shows the Fisher-test factors and significance of the individual (i.e., F, A, T) and interactive (i.e., $\mathrm{F}^{*} \mathrm{~A}, \mathrm{~T}^{*} \mathrm{~A}, \mathrm{~F}^{*} \mathrm{~T}, \mathrm{~F}^{*} \mathrm{~T}^{*} \mathrm{~A}$ ) effects of the predictors.

- Hypothesis decomposition graphs that show the correlation of each predictor or interactive effect vs. $\Delta \tau$.

As the final step, Principal Component Analysis (Statistica for Windows) was run using the $\Delta \tau$ from the TT-OMWW and $\mathrm{HPH}-\mathrm{OMWW}$ analysis, with the media supplemented with $5-15 \%$ of each treated OMWW.

\section{RESULTS}

The equation of Dantigny et al. (2011) satisfactorily fitted all of these datasets, with regression coefficients that ranged from 0.937 to 0.999 .

Table 2 gives the fitting parameters from the equation of Dantigny et al. (2011) for the 12 fungi tested here. These fungi showed different trends, mainly on the basis of their saprophytic and parasitic roles. A first group comprised L. theobromae, Pm. parasiticum, and D. amygdali, which are trunk disease pathogens of several fruit trees (Mostert et al., 2006; Diogo et al., 2010; Carlucci et al., 2015a,b). On the 15\% OMWW-supplemented agars, these three fungi generally experienced an increase in $\tau$ (TT-OMWW, $3.26 \pm 0.05$ days to $14.26 \pm 0.71$ days; HPHOMWW, $5.07 \pm 0.25$ days to $14.04 \pm 0.06$ days), with some 
TABLE 2 | Fungi grown on the laboratory media supplemented with either thermal-treated or high-pressure homogenized OMWW.

\begin{tabular}{|c|c|c|c|c|c|c|c|}
\hline \multirow[t]{3}{*}{ Fungal species } & \multicolumn{7}{|c|}{ Time to attain half maximum diameter on supplemented agar ( $\tau$, days) } \\
\hline & \multirow{2}{*}{$\frac{\text { Potato Dextrose }}{\text { Agar }}$} & \multicolumn{3}{|c|}{ Thermal treated OMWW agar (\%) } & \multicolumn{3}{|c|}{ High-pressure homogenized OMWW agar (\%) } \\
\hline & & 5 & 10 & 15 & 5 & 10 & 15 \\
\hline Alternaria alternata & $2.07 \pm 0.01 \mathrm{~A}$ & $3.03 \pm 0.03 B$ & $6.02 \pm 0.16 \mathrm{C}$ & $9.05 \pm 0.16 \mathrm{E}$ & $6.81 \pm 0.12 \mathrm{C}$ & $7.76 \pm 0.08 \mathrm{D}$ & $15.97 \pm 0.01 F$ \\
\hline Aspergillus niger & $4.11 \pm 0.14 \mathrm{~A}$ & $4.96 \pm 0.29 A, B$ & $5.72 \pm 0.27 \mathrm{~B}$ & $5.69 \pm 0.27 \mathrm{~B}$ & $4.65 \pm 0.21 \mathrm{~A}$ & $9.38 \pm 0.22 \mathrm{C}$ & $15.97 \pm 0.01 \mathrm{D}$ \\
\hline Aspergillus ochraceus & $10.25 \pm 0.29 D$ & $8.31 \pm 0.21 \mathrm{C}$ & $7.12 \pm 0.28 \mathrm{~B}$ & $22.21 \pm 0.60$ & $5.46 \pm 0.16 \mathrm{~A}$ & $9.85 \pm 0.21 \mathrm{D}$ & $15.89 \pm 0.01 E$ \\
\hline Colletotrichum gloeosporioides & $2.68 \pm 0.10 \mathrm{~A}$ & $3.99 \pm 0.12 B$ & $8.85 \pm 0.16 \mathrm{C}$ & $16.32 \pm 0.40 E$ & $8.51 \pm 0.20 \mathrm{C}$ & $11.05 \pm 0.22 \mathrm{D}$ & $22.00 \pm 0.10 F$ \\
\hline Diaporthe amygdali & $6.49 \pm 0.22 \mathrm{~B}$ & $3.65 \pm 0.13 \mathrm{~A}$ & $4.19 \pm 0.08 \mathrm{~A}$ & $6.47 \pm 0.14 \mathrm{~B}$ & $7.73 \pm 0.14 \mathrm{C}$ & $10.11 \pm 0.21 \mathrm{D}$ & $14.03 \pm 0.06 \mathrm{E}$ \\
\hline Fusarium oxysporum & $3.02 \pm 0.07 \mathrm{~B}$ & $1.90 \pm 0.01 \mathrm{~A}$ & $4.07 \pm 0.14 \mathrm{C}$ & $4.98 \pm 0.15 D$ & $6.27 \pm 0.24 \mathrm{E}$ & $7.44 \pm 0.07 \mathrm{~F}$ & $15.99 \pm 0.10 G$ \\
\hline Lasiodiplodia theobromae & $2.00 \pm 0.01 \mathrm{~A}$ & $1.78 \pm 0.0 \mathrm{~A} 3$ & $2.03 \pm 0.1 \mathrm{~A}$ & $3.26 \pm 0.05 B$ & $5.07 \pm 0.25 \mathrm{C}$ & $8.06 \pm 0.21 \mathrm{D}$ & $9.99 \pm 0.10 E$ \\
\hline Penicillium italicum & $5.32 \pm 0.38 \mathrm{~A}$ & $8.28 \pm 0.12 \mathrm{C}$ & $6.88 \pm 0.14 \mathrm{~A}, \mathrm{~B}$ & $7.28 \pm 0.15 B$ & $7.27 \pm 0.12 \mathrm{~B}$ & $7.26 \pm 0.11 \mathrm{~B}$ & $11.54 \pm 0.10 D$ \\
\hline Phaeoacremonium parasiticum & $10.78 \pm 0.14 \mathrm{C}$ & $6.96 \pm 0.15 \mathrm{~A}$ & $8.87 \pm 0.18 \mathrm{~B}$ & $14.26 \pm 0.71 \mathrm{D}$ & $9.14 \pm 0.19 \mathrm{~B}$ & $9.85 \pm 0.24 \mathrm{~B}, \mathrm{C}$ & $14.04 \pm 0.06 D$ \\
\hline Rosellinia necatrix & $3.46 \pm 0.02 \mathrm{~A}$ & $4.84 \pm 0.14 \mathrm{~B}$ & - & - & $7.65 \pm 0.16 \mathrm{C}$ & $9.9 \pm 0.02 \mathrm{D}$ & $11.55 \pm 0.10 \mathrm{E}$ \\
\hline Sclerotium rolfsii & $1.89 \pm 0.01 \mathrm{~A}$ & $7.54 \pm 0.03 \mathrm{~B}$ & $-^{\star}$ & - & $7.05 \pm 0.14 \mathrm{~B}$ & $7.51 \pm 0.13 \mathrm{~B}$ & $11.55 \pm 0.10 \mathrm{C}$ \\
\hline Trichoderma sp. & $1.81 \pm 0.02 \mathrm{~A}$ & $1.87 \pm 0.02 \mathrm{~A}$ & $2.05 \pm 0.10 \mathrm{~A}$ & $2.14 \pm 0.10 \mathrm{~A}$ & $2.93 \pm 0.17 \mathrm{~B}$ & $6.30 \pm 0.03 C$ & $15.95 \pm 0.01 \mathrm{D}$ \\
\hline
\end{tabular}

Data are means \pm standard error. The letters indicate the significant differences in each row (one-way ANOVA and Tukey's test, $P<0.05$ ).

${ }^{*}$ No growth.

exceptions: D. amygdali was not affected by TT-OMWW, while HPH-OMWW promoted increased $\tau$ in Pm. parasiticum only at $15 \%$, but it showed $\tau$ level lower than positive control in 5-10\% HPH-OMWW and TT-OMWW. C. gloeosporioides and A. alternata are the causal agents of anthracnose and black spot disease on olive drupes (Moral et al., 2008; Talhinhas et al., 2015), and these fungi were affected by both TT-OMWW and HPHOMWW, where $\tau$ ranged from $3.03 \pm 0.03$ days (5\%) to 16.32 \pm 0.04 days $(15 \%)$, and from $6.81 \pm 0.12$ days (5\%) to $22.0 \pm$ 0.10 days (15\%), respectively. F. oxysporum is a soil-borne fungus, and it was not affected by TT-OMWW at 5\%. Similarly, the growth of Trichoderma sp. was not influenced by TT-OMWW, while on HPH-OMWW, $\tau$ increased from $2.93 \pm 0.17$ days (5\%) to $15.95 \pm 0.01$ days (15\%). S. rolfsii and $R$. necatrix are severe soilborne fungal pathogens of horticultural crops and fruit trees, respectively, as reported by Lops et al. (2008) and Carlucci et al. (2013), and their growth was inhibited by 10 and $15 \%$ TT-OMWW.

A second group experienced different trends for $\tau$, where this was lower than the PDA positive control. A. ochraceus was characterized by lower $\tau$ on the media containing $5 \%$ and 10\% TT-OMWW and HPH-OMWW, and it was inhibited only with the 15\% TT-OMWW and HPH-OMWW, as seen by the increased $\tau$ to $22.21 \pm 0.60$ days and $15.89 \pm 0.01$ days, respectively, as well as $\mathrm{Pm}$. parasiticum. A similar situation was seen for $A$. niger, which used the phenolic compounds of TTOMWW for its growth more so than HPH-OMWW.

Although Table 2 offers an interesting overview of the growth kinetics of these fungi with TT-OMWW and HPH-OMWW, the fitting parameters for these different fungal species could not be simply compared. Thus, the $\tau$ values were standardized to provide $\Delta \tau$, in terms of their increases/decreases compared to the PDA positive control. Then, these $\Delta \tau$ were used to run multi-factorial ANOVA according to three different independent factors: the fungus (F), the percentage (amount) treated OMWWs added (A), and the OMWW treatments (T). Table 3 shows the statistical analysis and $F$-values for both of these individual and the interactive terms. These data indicate that $\Delta \tau$ was mainly affected by the amount of treated OMWWs added, followed by the fungal species, and finally by the OMWW treatments. For the interactive terms, the most significant effect was for the fungi versus OMWW treatment interaction $\left(\mathrm{F}^{*} \mathrm{~T}\right)$.

Another output of the multi-factorial approach is the decomposition of the trend of each factor, with this data shown in the hypothesis decomposition graphs (Figure 1). These show the quantitative effects of each independent factor. In terms of the fungal species (Figure 1A), some of these can be strongly inhibited by these OMWWs, such as C. gloeosporioides, S. rolfsii and $R$. necatrix (Figure 1A, Cgd, Sri, Rnx). The analysis defined their $\Delta \tau$ in the range from 8 to 10 days, thus indicating that their growth can be delayed by 8-10 days in comparison with their growth on PDA. Other fungi, such as Pm. parasiticum and A. ochraceus (Figure 1A, Pmp, Aoc), showed a lower $\Delta \tau$, thus suggesting that their growth was not affected by these treated OMWWs.

Figure 1B shows the quantitative effects of the amount of treated OMWW added, where, as expected, increasing the amounts of TT-OMWW and HPH-OMWW in the minimal media resulted in a general delay of fungal growth. Finally, the effects of the high-temperature and HPH treatments might increase or decrease the effects of TT-OMWW and HPHOMWW on the fungal growth (Figure 1C). Here, the HPHOMWW promoted increased bioactivity of the OMWW, with increased mean $\Delta \tau$ from 3.0 days to 4.8 days. This relies only on the effects of the OMWW treatment, and is independent of the other two factors (i.e., fungal species, amount of treated OMWW added). 
TABLE 3 | Multifactorial ANOVA run on the parameter $\Delta \tau$ (prolongation of $\tau$ with reference to the PDA positive control; days).

\begin{tabular}{lccccc}
\hline Factor & $\begin{array}{c}\text { Sum of } \\
\text { squares }\end{array}$ & $\begin{array}{c}\text { Degrees of } \\
\text { freedom }\end{array}$ & $\begin{array}{c}\text { Mean sum } \\
\text { of squares }\end{array}$ & Fisher test & $\boldsymbol{p}$ \\
\hline Intercept & 4478.16 & 1 & 4478.15 & 126769.3 & 0.00 \\
$\mathrm{~F}$ & 2578.06 & 11 & 234.37 & 6634.5 & 0.00 \\
$\mathrm{~T}$ & 175.70 & 1 & 175.70 & 4973.9 & 0.00 \\
$\mathrm{~A}$ & 1931.22 & 2 & 965.61 & 27334.8 & 0.00 \\
$\mathrm{~F}^{\star} \mathrm{T}$ & 1263.93 & 11 & 114.90 & 3252.7 & 0.00 \\
$\mathrm{~F}^{\star} \mathrm{A}$ & 639.48 & 22 & 29.07 & 822.8 & 0.00 \\
$\mathrm{~A}^{*} \mathrm{~T}$ & 72.82 & 2 & 36.41 & 1030.6 & 0.00 \\
$\mathrm{~F}^{*} \mathrm{~A}^{*} \mathrm{~T}$ & 691.42 & 22 & 31.43 & 889.7 & 0.00 \\
Error & 5.09 & 144 & 0.04 & & \\
\hline
\end{tabular}

F, effect of fungal species (Table 1); A, effect of amount of treated OMWWs (5, 10, 15\%); T, effect of OMWW treatments (TT-OMWW, HPH-OMWW).

As a final step, a multivariate approach was carried out to group the different fungal species and to select the most suitable ones for further studies. $\Delta \tau$ from the media supplemented with TT-OMWW and HPH-OMWW were used as the input values for this Principal Component Analysis, with the outputs illustrated in Figure 2A (variable projection) and Figure 2B (case projection).

The PC1 and PC2 factors accounted for $84.73 \%$ of the total variability (Figure 2A). Here, variables 5-T, 10- T, 5$\mathrm{HPH}$, and $10-\mathrm{HPH}$ (i.e., $\Delta \tau$ for the $5 \%$ and $10 \%$ TTOMWW and HPH-OMWW media) were mostly related to PC1 (correlations, 0.814-0.885), while variables 15-T and 15HPH showed similar correlations to both PC1 and PC2 (0.6120.671).

This principal component analysis highlighted two groups for the fungal species (Figure 2B). The first was in quadrants II and III and comprised C. gloeosporioides, A. alternata, $S$. rolfsii, and $R$. necatrix, the growth of which was strongly inhibited by the addition of the OMWWs. This group is not homogeneous, because on the media containing $15 \%$ treated OMWWs, some differences were seen. Here, S. rolfsii and $R$. necatrix were more affected by $15 \%$ TT-OMWW, while C. gloeosporioides and A. alternata were more affected by $15 \%$ $\mathrm{HPH}-\mathrm{OMWW}$.

The second group of fungal species was in quadrant I, and included A. ochraceus and Pm. parasiticum. These two fungi were resistant to the treated OMWWs, and showed negative $\Delta \tau$ (i.e., stimulation of fungal growth by treated OMWWs). Finally, there is the remaining miscellaneous group that included the fungi with variable trends: L. theobromae, F. oxysporum, P. italicum, A. niger, Trichoderma sp., and D. amygdali.

As a last step, some preliminary chemical analyzed were done on OMWW. The control batch had a value of phenols of $11.25 \pm 0.77 \mathrm{~g} \mathrm{~L}^{-1}$; this parameter increased to $16.34 \pm 0.32 \mathrm{~g}$ $\mathrm{L}^{-1}$ in TT-OMWW, whereas it was at $10.99 \mathrm{~g} \mathrm{~L}^{-1}$ in $\mathrm{HPH}-$ OMWW. The Folin's method only assesses the total amount of phenols; however, this preliminary result could suggest a possible degradation of complex phenols because of the thermal treatment with an increase of the total phenolic compounds.

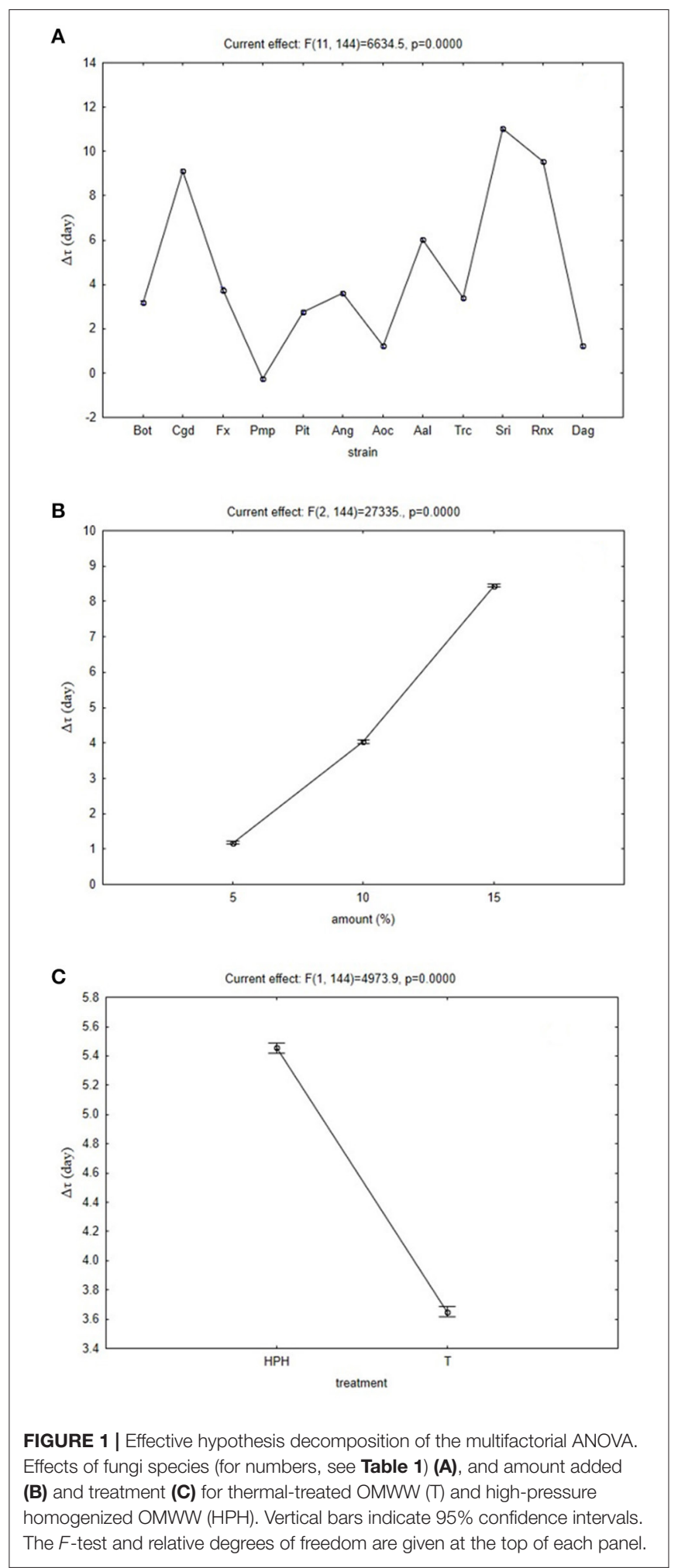

This process probably did not occur in HPH-OMWW, as the amount of phenols was not significantly different from the untreated batch. The content of proteins was at $373.05 \pm 9.43 \mu \mathrm{g}$ $\mathrm{mL}^{-1}$ and was not affected by the kind of treatment. 

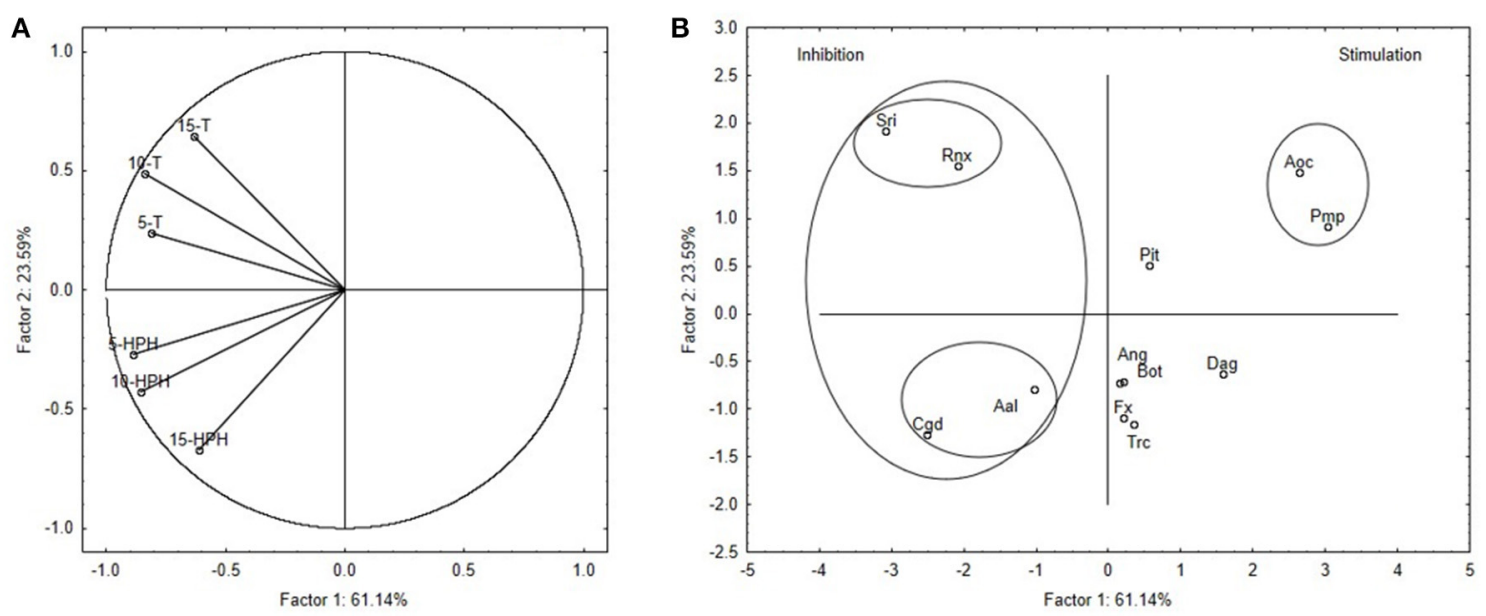

FIGURE 2 | Principal Component Analysis run on $\Delta \tau$ values. (A) Projection of variables. Codes indicate percentage addition of thermal-treated OMWW (T) and high-pressure homogenized OMWW (HPH). (B) Projection of cases. For fungal species, see Table 1.

\section{DISCUSSION}

In recent years, several studies have evaluated OMWWs in different sectors, including agriculture, bioenergy production, bioconversion, and extraction of the valuable phytochemical compounds in OMWWs (Christodoulou et al., 2008; El Hajjouji et al., 2008; Ntaikou et al., 2009; Dermeche et al., 2013). To date, various physicochemical, biological, and combined technologies have also been applied to OMWW residues, to reduce their pollutant effects, including precipitation, coagulation, extraction, sedimentation, ion exchange, adsorption on active carbon, chemical and advanced oxidation, centrifugation and ultrafiltration, advanced oxidation processes and ultrafiltration, fungal pretreatment, and anerobic digestion and ultrafiltration (Jaouad et al., 2016). The most suitable treatment for these OMWWs and their residues on any large scale appears to be the conventional activated sludge process (Sipma et al., 2010). The activated sludge processes produce a large amount of excess sludge, which may cause a serious of environmental and health issues (Zhang et al., 2009; Luo et al., 2013). However, application of this kind of treatment to biodegradation of OMWWs might not be effective because the phenolic compounds present can inhibit the microbial metabolism of the sludge. Aerobic biological treatments using different microorganisms, including fungi (Dias et al., 2004) or bacteria (Knupp et al., 1996), are widely used and environmentally friendly.

The present study addresses the use of OMWW in agriculture to control fungal growth, with the second aim to determine the effects of two initial treatments on the bioactivities of the OMWW. Based on these data, the tested fungal species generally followed two trends. The first was for an increased $\tau$ for either the TT-OMWW or HPH-OMWW media. This indicates that these TT-OMWW and HPH-OMWW can have positive effects in the control of these fungal pathogens, through their polyphenols content.
$\mathrm{HPH}$ pretreatment can improve the sludge anaerobic digestion, above all if combined with an alkaline $\mathrm{pH}$ (Fang et al., 2014); pressure and number of cycles influence the effect of $\mathrm{HPH}$, as they both improve sludge disintegration (Zhang et al., 2012). At high pressure and with repeated HPH-cycles, the disintegration degree and soluble chemical oxygen demand increased, thus resulting a release of organic matter (Fang et al., 2015).

Eight of the 12 fungi investigated here showed major slowing of their growth on HPH-OMWW: L. theobromae, D. amygdali, C. gloeosporioides, A. alternata, F. oxysporum, Trichoderma sp., $S$. rolfsii, and $R$. necatrix. These data are in agreement with Telles et al. (2017), who studied the profiles of phenolic compounds and their relationships with the defense mechanisms of bean against fungal contamination and the amylase inhibitory activity from fungi. They reported that the phenolic compounds could potentially inhibit fungal attack and/or prevent aflatoxin production in bean. Moreover, plant defense against fungal infection is influenced by different biotic and abiotic factors, such as the phenolic composition of specific plant tissues, which can prevent pathogen attacks (Mendes et al., 2013). The aromatic ring of phenols, along with - $\mathrm{OH}$ groups, play a major role in plant defense mechanisms (Richardson, 1980; Guajardo-Flores et al., 2013; Ramírez-Jiménez et al., 2014; Wang et al., 2015). Lambert et al. (2012) studied the antifungal role of phenols against grapevine wood decay against trunk disease fungi and found that hydroxystilbenoids and vitisin A and B significantly inhibited fungal growth, except for Pm. aleophilum and Pm. parasiticum.

Altintas et al. (2013) assessed the composition and the antibacterial and antifungal activities of Origanum essential oils. Thymol and carvacrol were the major components of this oil and exerted a significant effect on strawberry anthracnose-causing fungal plant pathogens Colletotrichum acutatum, C. fragariae, and C. gloeosporioides using the direct overlay bioautography 
assay. Thymol demonstrated antifungal activity and produced growth inhibition of Phomopsis obscurans (Ellis \& Everh.) B. Sutton in experimental conditions, such as D. amygdali in our research. They suggested that fungi (and many other organisms) do not always respond to chemical agents in a concentration-dependent manner. Mean fungal growth of thymol and carvacrol tested separately and mixed together indicated that these phenolic compounds are not good natural fungicides, while the bioassay data indicated that thymol and carvacrol may act more as growth suppressive compounds in the plant and not as fungitoxic defense compounds against invading pathogens.

Other researchers have found that phenolic compounds can inhibit Alternaria spp. (Brenes et al., 2011); F. oxysporum (Patel and Saraf, 2017); Trichoderma sp. (Zheng et al., 2017); R. necatrix (Lee, 2000).

For the antifungal effects of OMWWs, the data from the present study are in line with the findings of Lops et al. (2008) for S. rolfsii, the causal fungal agent of collar rots as soil-borne pathogens of horticultural crops.

The second trend that was recorded in the present study was showed for A. ochraceus and Pm. parasiticum, which experienced decreased $\tau$ when grown on both TT-OMWW and $\mathrm{HPH}-\mathrm{OMWW}$ at $5 \%$ and $10 \%$. This defines a positive effect of the phenols on fungal growth, as previously reported by Bevilacqua et al. (2017). Martínková et al. (2016) reported that new promising wild-type producers have emerged of the enzymes for the degradation of phenols in model mixtures or real wastewaters and a number of recombinant strains were also constructed, based mainly on yeasts or Aspergillus strains as hosts, indeed a variety of processes were proposed at the lab scale for using these fungi and their phenol oxidases in the bioremediation.

Not ligninolytic Aspergillus species colonize soils and sediments contaminated with toxic chemicals. Thus, they could be goof tool for the bioremediation, because of their nonylphenol metabolism. The removal of nonylphenol by A. versicolor from waste and water pollutants can be used in bioreactors or on largescale in sewage treatment plants where the fungus can be used as an inoculum for bioremediation processes (Krupinski et al., 2014).

In the same way, Sivasubramanian and Namasivayam (2015) developed a microbial consortium consisting of five phenol-degrading strains isolated from environmental source. The consortium could degrade $99 \%$ of $1,000 \mathrm{mg} \mathrm{L}^{-1}$ phenol after $72 \mathrm{~h}$ incubation with a biomass increase from $2.6 \times 10^{7}$ to 4 $\times 10^{12} \mathrm{CFU} \mathrm{mL}{ }^{-1}$. Characterization of the members revealed that consortium consisted of Candida tropicalis $\left(1.2 \times 10^{5} \mathrm{CFU}\right.$

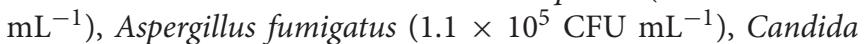
albicans $\left(3.0 \times 10^{3} \mathrm{CFU} \mathrm{\textrm {mL } ^ { - 1 }}\right)$, Candida haemulonis $\left(2.6 \times 10^{3}\right.$

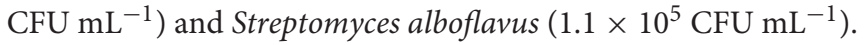

Another interesting finding in the present study was the different effects of the thermal treatment and $\mathrm{HPH}$ on the antifungal activities of these OMWWs. The statistical analysis suggests stronger bioactivity for HPH-OMWW, potentially due to preservation of the phenols through the treatment, as indicated by Varela-Santos et al. (2012).

The production of OMWW is seasonal, and in October to December, large volumes of OMWW are produced. These are strongly contaminated by a composite microbiota of bacteria, yeast, and fungi (McNamara et al., 2008), and storage of OMWW at room temperature or under refrigeration generally results in degradation of the phenolic compounds (Sinigaglia et al., 2010). Therefore, OMWW should be initially treated before storage, to assure longer use and bioactive potential. This study represents the first report on the evaluation of the effects of different stabilization approaches carried out for the OMWW raw material, where HPH appears to be a promising way forward. However, the results here and the effects of TT-OMWW on some of these fungi suggest that the effects of OMWW, as well as the influence of the initial treatments, also depend upon the fungal species. Indeed, some of these fungi were strongly affected by TT-OMWW, which thus suggests that the decomposition metabolites that originate from the thermal treatment might also have roles in the antifungal activity of TT-OMWW.

In conclusion, the disposal of OMWW represents a challenge for the environment, although it might also be an opportunity. This study addressed the use of low amounts of OMWWs, which can be used to counteract the effects of some soilborne and/or pathogenic fungi in agriculture, including $L$. theobromae, Pm. parasiticum, D. amygdali, C. gloeosporioides, A. alternata, F. oxysporum, Trichoderma sp., S. rolfsii, and $R$. necatrix. In addition, two initial treatments of OMWW (temperature, HPH) were studied to determine whether they influence the bioactivities of the resulting OMWWs. These data suggest general improved benefits following $\mathrm{HPH}$, as probable positive effects of the phenols, although there are some exceptions to this generalized statement.

\section{AUTHOR CONTRIBUTIONS}

MC, MS, AC, and AB: conceived this study; FC, MR, DC, and CC: performed the analyses. $\mathrm{AB}$ and $\mathrm{MC}$ : performed the statistical analyses; FC and AB: wrote the paper; MC: funded the research; All authors edited and approved the final manuscript.

\section{FUNDING}

The research was supported by the Italian Ministry of Education, University and Research (MIUR) through the grant ECO_P4 Promotion of ECO-friendly processes for the enhancement of quality of Apulian food productions (PON02_00186_2866121) (P.O.N. RICERCA E COMPETITIVITA' 2007-2013 per le Regioni della Convergenza-Avviso n. 713/Ric. del 29/10/2010-Titolo II-“Sviluppo/Potenziamento di DAT e di LPP”). 


\section{REFERENCES}

Altintas, A., Tabanca, N., Tyihák, E., Ott, P. G., Móricz, A. M., Mincsovics, E., et al. (2013). Characterization of volatile constituents from origanum onites and their antifungal and antibacterial activity. J. AOAC Int. 96, 1200-1208. doi: 10.5740 /jaoacint.SGEAltintas

Amador-Espejo, G. G., Suàrez-Berencia, A., Juan, B., Bárcenas, M. E., and Trujillo, A. J. (2014). Effect of moderate inlet temperatures in ultra-high-pressure homogenization treatments on physicochemical and sensory characteristics of milk. J. Dairy Sci. 97, 659-671. doi: 10.3168/jds.2013-7245

Bevilacqua, A., Cibelli, F., Raimondo, M. L., Carlucci, A., Lops, F., Sinigaglia, M., et al. (2017). Fungal bioremediation of olive mill wastewater: using a multi-step approach to model inhibition or stimulation. J. Sci. Food Agric. 97, 461-468. doi: $10.1002 /$ jsfa.7747

Bradford, M. M. (1976). A rapid and sensitive method for the quantification of microgram quantities of protein using the principle of protein-dye binding. Anal. Biochem. 72, 248-255. doi: 10.1016/0003-2697(76)90527-3

Bray, H. G., and Thrope, W. V. (1954). Methods of biochemical analysis. Interscience 1, 27-25.

Brenes, M., García, A., de los Santos, B., Medina, E., Romero, C., de Castro, A., et al. (2011). Olive glutaraldehyde-like compounds against plant pathogenic bacteria and fungi. Food Chem. 125, 1262-1266. doi: 10.1016/j.foodchem.2010.10.055

Calligaris, S., Foschia, M., Bartolomeoli, I., Maifreni, M., and Manzocco, L. (2012). Study on the applicability of high-pressure homogenization for the production of banana juices. LWT Food Sci. Technol. 45, 117-121. doi: 10.1016/j.lwt.2011.07.026

Carlucci, A., Cibelli, F., Lops, F., and Raimondo, M. L. (2015a). Characterization of Botryosphaeriaceae species as causal agents of trunk diseases on grapevines. Plant Dis. 99, 1678-1688. doi: 10.1094/PDIS-03-15-0286-RE

Carlucci, A., Lops, F., Cibelli, F., and Raimondo, M. L. (2015b). Phaeoacremonium species associated with olive wilt and decline in southern Italy. Eur. J. Plant Pathog. 141, 717-729. doi: 10.1007/s10658-014-0573-8

Carlucci, A., Manici, L. M., Colatruglio, L., Caputo, A., and Frisullo, S. (2013). Rosellinia necatrix attack according to soil features in the mediterranean environment. For. Pathol. 43, 12-18. doi: 10.1111/j.1439-0329.2012.00787.x

Carlucci, A., Raimondo, M. L., Santos, J., and Phillips, A. J. L. (2012). Plectospherella species associated with root and collar rots of horticultural crops in southern Italy. Persoonia 28, 34-48. doi: 10.3767/003158512X638251

Christodoulou, V., Bampidis, V. A., Israilides, C. J., Robinson, P. H., Giouzelyiannis, A., and Vlyssides, A. (2008). Nutritional value of fermented olive wastes in growing lamb rations. Anim. Feed Sci. Technol. 141, 375-383. doi: 10.1016/j.anifeedsci.2007.06.026

Dantigny, P., Nanguy, S. P. M., Judet-Correia, D., and Bensoussan, M. (2011). A new model for germination of fung0i. Int. J. Food Microbiol. 146, 176-181. doi: 10.1016/j.ijfoodmicro.2011.02.022

De Clerk, J. (1963). Course de Brasserie, 2nd Edn. Louvain-la-Neuve-Belgium: Universitè catholique de Louvain.

Dermeche, S., Nadour, M., Larroche, C., Moulti-Mati, F., and Michaud, P. (2013). Olive mill wastes: biochemical characterization and valorization strategies. Process Biochem. 48, 1532-1552. doi: 10.1016/j.procbio.2013.07.010

Dias, A. A., Bezerra, R. M., and Pereira, A. N. (2004). Activity and elution profile of laccase during biological decolorization and dephenolization of olive mill wastewater. Bioresour. Technol. 92, 7-13. doi: 10.1016/j.biortech.2003.08.006

Diogo, E. L. F., Santos, J. M., and Phillips, A. J. L. (2010). Phylogeny, morphology and pathogenicity of Diaporthe and Phomopsis species on almond in Portugal. Fung. Divers. 44, 107-115. doi: 10.1007/s13225-010-0057-x

Disciglio, G., Gatta, G., Libutti, A., Gagliardi, A., Carlucci, A., Lops, F., et al. (2015). Effect of irrigation with treated agro-industrial wastewater on soil chemical characteristics and fungal populations during processing tomato crop cycle. J. Soil Sci. Plant Nutr. 15, 765-780. doi: 10.4067/S0718-95162015005000052

El Hadrami, A., Belaqziz, M., El Hassni, M., Hanifi, S., Abbad, A., Capasso, R., et al. (2004). Physico-chemical characterization and effects of olive oil mill wastewater fertirrigation on the growth of some Mediterranean crops. J. Agron. 3, 247-254. doi: 10.3923/ja.2004.247.254

El Hajjouji, H., Ait Baddi, G., Yaacoubi, A., Hamdi, H., Winterton, P., Revel, J. C., et al. (2008). Optimisation of biodegradation conditions for the treatment of olive mill wastewater. Bioresour. Technol. 99, 5505-5510. doi: 10.1016/j.biortech.2007.11.005
Fang, W., Zhang, P., Ye, J., Wu, Y., Zhang, H., Liu, J., et al. (2015). Physicochemical properties of sewage sludge disintegrated with high pressure homogenization. Int. Biodeterat. Biodegrad. 102, 126-130. doi: 10.1016/j.ibiod.2015.02.030

Fang, W., Zhang, P., Zhang, G., Jin, S., Li, D., Zhang, M., et al. (2014). Effect of alkaline addition on anaerobic sludge digestion with combined pretreatment of alkaline and high pressure homogenization. Bioresour. Technol. 168, 167-172. doi: 10.1016/j.biortech.2014.03.050

Garibaldi, A., and Gullino, M. L. (1995). Focus on critical issues in soil and substrate disinfestations towards the year 2000. Acta Horticult. 382, 21-36. doi: 10.17660/ActaHortic.1995.382.2

Guajardo-Flores, D., Serna-Saldívar, S. O., and Gutiérrez-Uribe, J. A. (2013). Evaluation of the antioxidant and antiproliferative activities of extracted saponins and flavonols from germinated black beans (Phaseolus vulgaris L.). Food Chem. 141, 1497-1503. doi: 10.1016/j.foodchem.2013.04.010

Jaouad, Y., Villain, M., Ouazzani, N., Mandi, L., and Marrot, B. (2016). Biodegradation of olive mill wastewater in a membrane bioreactor: acclimation of the biomass and constraints. Desalinat. Water Treat. 57, 8109-8118. doi: 10.1080/19443994.2015.1025435

Knupp, G., Rücker, G., Ramos-Cormenzana, A., Garrido-Hoyos, S., Neugebauer, M., and Ossenkop, T. (1996). Problems of identifying phenolic compounds during the microbial degradation of olive mill wastewater. Int. Biodeternat. Biodegrad. 38, 277-282. doi: 10.1016/S0964-8305(96)00062-5

Krupinski, M., Janicki, T., Pałecz, B., and Długonski, J. (2014). Biodegradation and utilization of 4-n-nonylphenol by Aspergillus versicolor as a sole carbon and energy source. J. Hazard. Mater. 280, 678-684. doi: 10.1016/j.jhazmat.2014.08.060

Lambert, C., Bisson, J., Waffo-Téguo, P., Papastamoulis, Y., Richard, T., CorioCostet, M.-F., et al. (2012). Phenolics and their antifungal role in grapevine wood decay: focus on the botryosphaeriaceae family. J. Agr. Food Chem. 60, 11859-11868. doi: 10.1021/jf303290g

Lee, Y. S. (2000). Qualitative evaluation of ligninolytic enzymes in xylariaceous fungi. J. Microbiol. Biotechnol. 10, 462-469.

Lops, F., Carlucci, A., Colatruglio, L., and Frisullo, S. (2008). Uso di scarti solidi e liquidi della molitura delle olive nella lotta contro Sclerotium rolfsii. Proc. Giorn. Phytopathol. 2, 541-546.

Luo, K., Ye, Q., Yi, X., Yang, Q., Li, X.-M., Chen, H., et al. (2013). Hydrolysis and acidification of waste-activated sludge in the presence of biosurfactant rhamnolipid: effect of pH. Appl. Microb. Biotechnol. 97, 5597-5604. doi: 10.1007/s00253-012-4378-4

Manici, L. M., Caputo, F., and Bambini, V. (2004). Effect of green manure on Pythium spp. population and microbial communities in intensive cropping systems. Plant Soil 263, 133-142. doi: 10.1023/B:PLSO.0000047720.40918.29

Marrara, G., Tamburino, V., and Zimbone, S. M. (2002). "Storage and land application of olive oil mill wastewater: experiences in Calabria. Paper no. 026136," in Proceedings of the 95th Annual Meeting in American Society of Agricultural and Biological Engineers (Chicago, IL).

Martínková, L., Kotik, M., Marková, E., and Homolka, L. (2016). Biodegradation of phenolic compounds by Basidiomycota and its phenol oxidases: a review. Chemosphere 149, 373-382. doi: 10.1016/j.chemosphere.2016.01.022

McNamara, C. J., Anastasious, C. C., O’Flaherty, V., and Mitchell, R. (2008). Bioremediation of olive mill wastewater. Int. Biodeteriorat. Biodegrad. 61, 127-134. doi: 10.1016/j.ibiod.2007.11.003

Mekki, A., Dhouib, A., Aloui, F., and Sayadi, S. (2006). Olive wastewater as an ecological fertilizer. Agron. Sustain. Dev. 26, 61-67. doi: 10.1051/agro:2005061

Mendes, G. R. L., Alves, C. L., Cavalheiro, P., and Badiale-Furlong, E. (2013). Ação antifúngica de inibidores de $\alpha$ amilase extraídos de trigo (Triticuma estivum L.). Biochem. Biotechnol. Rep. 2, 79-81. doi: 10.5433/2316-5200.2013v2n3espp79

Moral, J., De La Rosa, R., León, L., Barranco, D., Michailides, T. J., and Trapero, A. (2008). High susceptibility of olive cultivar FS-17 to Alternaria alternata in southern Spain. Plant Dis. 92:1252. doi: 10.1094/PDIS-92-8-1252A

Morillo, J. A., Antizar-Ladislao, B., Monteoliva-Sánchez, M., Ramos-Cormenzana, A., and Russell, N. J. (2009). Bioremediation and biovalorisation of olive-mill wastes. Appl. Microbiol. Biotechnol. 82, 25-39. doi: 10.1007/s00253-008-1801-y

Mostert, L., Groenewald, J. Z., Summerbell, R. C., Gams, W., and Crous, P. W. (2006). Taxonomy and pathology of Togninia (Diaporthales) and its Phaeoacremonium anamorphs. Stud. Mycol. 54, 1-115. doi: 10.3114/sim.54.1.1

Niaounakis, M., and Halvadakis, C. P. (2006). Olive Processing Waste Management: Literature Review and Patent Survey, 2nd Edn. Amsterdam: Elsevier. 
Ntaikou, I., Kourmentza, C., Koutrouli, E. C., Stamatelatou, K., Zampraka, A., Kornaros, M., et al. (2009). Exploitation of olive oil mill wastewater for combined biohydrogen and biopolymers production. Bioresour. Technol. 100, 3724-3730. doi: 10.1016/j.biortech.2008.12.001

Patel, S., and Saraf, M. (2017). Biocontrol efficacy of Trichoderma asperellum MSST against tomato wilting by Fusarium oxysporum f. sp. lycopersici. Arch. Phytopathol. Plant Protect. 50, 228-238. doi: 10.1080/03235408.2017.1287236

Ramírez-Jiménez, A. K., Reynoso-Camacho, R., Mendonza-Díaz, S., and LoarcaPi-a, G. (2014). Functional and technological potential of dehydrated Phaseolus L. flours. Food Chem. 161, 254-260. doi: 10.1016/j.foodchem.2014.04.008

Richardson, M. (1980). Protein inhibitors of enzymes. Food Chem. 6, 235-253. doi: 10.1016/0308-8146(81)90012-1

Sinigaglia, M., Di Benedetto, N., Bevilacqua, A., Corbo, M. R., Capece, A., and Romano, P. (2010). Yeasts isolated from olive mill wastewaters from southern Italy: technological characterization and potential use for phenol removal. Appl. Microbiol. Biotechnol. 87, 2345-2354. doi: 10.1007/s00253-010-2684-2

Sipma, J., Osuna, B., Collado, N., Monclús, H., Ferrero, G., Comas, J., et al. (2010). Comparison of removal of pharmaceuticals in MBR and activated sludge systems. Desalination 250, 653-659. doi: 10.1016/j.desal.2009. 06.073

Sivasubramanian, S., and Namasivayam, S. K. R. (2015). Phenol degradation studies using microbial consortium isolated from environmental sources. J. Environ. Chem. Eng. 3, 243-252. doi: 10.1016/j.jece.2014.12.014

Suárez-Jacobo, Á., Gervilla, R., Guamis, B., Roig-Sagués, A. X., and Saldo, J. (2010). Effect of UHPH on indigenous microbiota of apple juice: a preliminary study of microbial shelf-life. Int. J. Food Microbiol. 136, 261-267. doi: 10.1016/j.ijfoodmicro.2009.11.011

Talhinhas, P., Gonçalves, E., Sreenivasaprasad, S., and Oliveira, H. (2015). Virulence diversity of anthracnose pathogens (Colletotrichum acutatum and C. gloeosporioides species complexes) on eight olive cultivars commonly grown in Portugal. Eur. J. Plant Pathol. 142, 73-83. doi: 10.1007/s10658-0140590-7

Telles, A. C., Kupski, L., and Badiale-Furlong, E. (2017). Phenolic compounds in beans as protection against mycotoxins. Food Chem. 214, 293-299. doi: 10.1016/j.foodchem.2016.07.079

Varela-Santos, E., Ochoa-Martinez, A., Tabilo-Munizaga, G., Reyes, J. E., PérezWon, M., Briones-Labarca, V., et al. (2012). Effect of high hydrostatic pressure (HHP) processing on physicochemical properties, bioactive compounds and shelf-life of pomegranate juice. Innov. Food Sci. Emerg. Technol. 13, 13-22. doi: $10.1016 /$ j.ifset.2011.10.009
Velázquez-Estrada, R. M., Hernández-Herrero, M. M., Rüfer, C. E., GuamisLópez, B., and Roig-Sagués, A. X. (2013). Influence of ultra-high-pressure homogenization processing on bioactive compounds and antioxidant activity of orange juice. Innov. Food Sci. Emerg. Technol. 18, 89-94. doi: $10.1016 /$ j.ifset.2013.02.005

Wang, W., Guo, J., Zhang, J., Peng, J., Lui, T., and Xin, Z. (2015). Isolation, identification and antioxidant activity of bound phenolic compounds present in rice bran. Food Chem. 171, 40-49. doi: 10.1016/j.foodchem.2014.08.095

Wibowo, S., Grauwet, T., Santiago, J. S., Tomic, J., Vervoort, L., Hendrickx, M., et al. (2015). Quality changes of pasteurised orange juice during storage: a kinetic study of specific parameters and their relation to colour instability. Food Chem. 187, 140-151. doi: 10.1016/j.foodchem.2015.03.131

Xi, J., Shen, D., Zhao, S., Lu, B., Li, Y., and Zhang, R. (2009). Characterization of polyphenols from green tea leaves using a high hydrostatic pressure extraction. Int. J. Pharm. 382, 139-143. doi: 10.1016/j.ijpharm.2009.08.023

Yu, Y., Xu, Y., Wu, J., Xiao, G., Fu, M., and Zhang, Y. (2014). Effect of ultra-highpressure homogenisation processing on phenolic compounds, antioxidant capacity and antiglucosidase of mulberry juice. Food Chem. 153, 114-120. doi: 10.1016/j.foodchem.2013.12.038

Zhang, G., Yang, J., Liu, H., and Zhang, J. (2009). Sludge ozonation: disintegration, supernatant changes and mechanisms. Bioresour. Technol. 100, 1505-1509. doi: 10.1016/j.biortech.2008.08.041

Zhang, Y., Zhang, P., Ma, B., Wu, H., Zhang, S., and Xu, X. (2012). Sewage sludge disintegration by high-pressure homogenization: a sludge disintegration model. J. Environ. Sci. 24, 814-820. doi: 10.1016/S1001-0742(11)60834-6

Zheng, W., Zheng, Q., Xue, Y., Hu, J., and Gao, M.-T. (2017). Influence of rice straw polyphenols on cellulase production by Trichoderma reesei. J. Biosci. Bioeng. 123, 731-738. doi: 10.1016/j.jbiosc.2017.01.009

Conflict of Interest Statement: The authors declare that the research was conducted in the absence of any commercial or financial relationships that could be construed as a potential conflict of interest.

Copyright (C) 2017 Cibelli, Bevilacqua, Raimondo, Campaniello, Carlucci, Ciccarone, Sinigaglia and Corbo. This is an open-access article distributed under the terms of the Creative Commons Attribution License (CC BY). The use, distribution or reproduction in other forums is permitted, provided the original author(s) or licensor are credited and that the original publication in this journal is cited, in accordance with accepted academic practice. No use, distribution or reproduction is permitted which does not comply with these terms. 